\title{
Spinoza, potencias de lo común *
}

\author{
Spinoza, power of the common
}

\author{
Por: Monetti, Sofía* \\ Universidad de la República \\ Montevideo, Uruguay \\ Email: sofimonet@gmail.com
}

Fecha de recepción: 15/04/2019

Fecha de aprobación: 21/05/2020

DOI: $\underline{10.30972 / n v t .1614346}$

\section{Resumen}

La filosofía de Spinoza ha sido referencia para numerosas producciones dentro y fuera de la filosofía, encontrando desde siglo XX y en nuestra actualidad una especial intensificación de su expansión. Quizás uno de los motivos que convoca a su lectura es el carácter libertario y autónomo de su pensamiento que abre nuevas posibilidades de configuración de campos y prácticas ético-políticas. Pueden tenderse muchas líneas de identificación para la relevancia del pensamiento spinoziano y para mostrar su contemporaneidad, en este trabajo se afirma su actualidad en el gesto mismo de poner a funcionar relaciones de su pensamiento. Spinoza deviene un pensador contemporáneo en la medida en que las relaciones que afirma se actualizan en la trama de un pensamiento sobre nuestro presente.

Este trabajo afirma la potencia de novedad que porta el spinozismo y lo hace en relación a la pregunta por lo común y por los modos de producción de comunidad que aparece con fuerza en nuestro escenario actual, como parte de múltiples reflexiones en ocasión de interrogar acerca de la vida colectiva y su organización política. Frente a

\footnotetext{
* El presente artículo forma parte parte del proceso de investigación realizado en el marco de la formación de la Maestría en Psicología Social de la Universidad de la República (Uruguay).

* Licenciada en Filosofía por la Universidad de la República, Uruguay. Maestranda en Psicología Social. Becaria Agencia Nacional de Investigación e Innovación (POS_NAC_2018_1_152269)
} 
un diagnóstico de crisis de las formas instituidas de lo colectivo, se presenta la cuestión de lo común como ocasión singular para pensar la vida colectiva, y la filosofía de Spinoza tiene una especial complicidad con esta pregunta y potencias innovativas aún por efectuarse en relación a ella.

Palabras clave: Spinoza; actualidad; común; comunidad; política

\section{Abstract}

Spinoza's philosophy has been a reference for numerous productions within and outside the philosophy, finding since the 20th century and nowadays a special intensification of its expansion. Perhaps one of the reasons that summons to its reading is the libertarian and autonomous character of its thought that opens new possibilities of configuration of ethical-political fields and practices. Many lines of identification can be drawn for the relevance of Spinozian thought and to show its contemporaneity, this work affirms its actuality in the very gesture of putting relationships of its thought to work. Spinoza becomes a contemporary thinker to the extent that the relationships he affirms are updated in the fabric of thought about our present. This work affirms the power of novelty that Spinozism carries and does so in relation to the question of the common and the modes of production of community that appears with force in our current scenario, as part of multiple reflections on the occasion of questioning about collective life and its political organization. Faced with a diagnosis of the crisis of the instituted forms of the collective, the question of the common is presented as a singular occasion to think about collective life, and Spinoza's philosophy has special complicity with this question and innovative powers yet to be realized in relation to it.

Keywords: Spinoza; actuality; common; community; politics

\section{Cómo citar este artículo:}

APA: Monetti, S. (2020). Spinoza, potencias de lo común. Nuevo Itinerario, 16 (1), 75-103. Recuperado de: (agregar dirección web) 


\section{Sofía Monetti}

\section{Introducción}

El pensamiento de Baruch Spinoza ha encontrado diversas resonancias desde sus primeras formulaciones, siendo un lugar de referencia tanto para la filosofía como para disciplinas y prácticas no filosóficas. En nuestra contemporaneidad se ha incrementado e intensificado la lectura atenta de su obra en trama con interrogantes políticas y filosóficas que emergen de nuestro presente.

Asistimos a una época donde las formas instituidas de generar lazos sociales se encuentran cuestionadas y dan lugar a la emergencia de nuevas modalidades, no anticipables, que cristalizan en el campo social.

Aparece con fuerza la pregunta por lo común como parte de múltiples reflexiones en ocasión de interrogar acerca de la vida colectiva y su organización política. En el concepto de lo común se expresan modos de comprensión de lo colectivo y de la relación individuo-colectivo, por lo que se inscribe en un campo de tensiones políticas actuales y en una serie de procesos de transformación de la vida colectiva.

El campo del spinozismo genera para nosotros la oportunidad de abrir las formas instituidas de comprensión del ejercicio político y desplegar potencias de lo colectivo aún por efectuarse.

Buena parte de las luchas sociales contemporáneas encuentran expresión en la defensa de lo común. En algunos casos se trata de la defensa de un bien común como un recurso natural, en otros se trata de defender lo común como el lugar de lo público no estatal, en otros casos refiere a la defensa de prácticas de construcción de comunidad. Todos estos sentidos, y muchos otros, configuran hoy un campo político donde se pone en escena la pregunta por lo común, habilitando la emergencia de nuevas prácticas y modos de comprensión.

En el escenario filosófico lo común es punto de convergencia de diversos debates, donde se encuentran y desencuentran distintas perspectivas. Varios autores 
contemporáneos como Antonio Negri, Giorgio Agamben, Paolo Virno, Jean-Luc Nancy, Maurice Blanchot, entre otros, afirman que asistimos hoy a una crisis de lo común.

Las formas que antes parecían garantizarles a los hombres un contorno común, que le aseguraban al lazo social alguna consistencia, perdieron su pregnancia y entraron definitivamente en colapso, desde la llamada esfera pública hasta los modos de asociación consagrados: comunitarios, nacionales, ideológicos, partidarios, sindicales (Pelbart, 2009, p. 21).

Nos es necesario volver a interrogarnos sobre las figuras de lo colectivo y pensar la cuestión de lo común nos genera una posibilidad particular para realizar este ejercicio.

El pensamiento de Spinoza, un filósofo del siglo XVII, tiene para nosotros hoy el carácter de contemporaneidad, en la medida en que nos permite desarrollar estas preguntas inaugurando un campo de prácticas novedoso. El campo del spinozismo, en su singular modo de comprender la constitución del cuerpo político, nos aporta una perspectiva muy valiosa para poder abonar a un pensamiento creativo y activo que habilite la producción de nuevos modos de hacer mundo.

El presente trabajo propone mostrar la actualidad del pensamiento de Spinoza y su singular relevancia para pensar en las condiciones de lo común y orientarnos en la posibilidad de efectuar una respuesta como experiencia colectiva de producción de comunidad.

\section{La actualidad del pensamiento spinoziano}

Afirmar la contemporaneidad de la filosofía de Baruch Spinoza puede decirse en varios sentidos. Puede señalarse la producción de obras referidas a su pensamiento, que alcanza una extensión extremadamente prolífica en nuestros días, dentro y fuera de la filosofía, dentro y fuera de la academia.

La potencia expansiva del pensamiento spinoziano se encuentra presente desde sus orígenes en los primeros "círculos spinozianos" donde el pensamiento del 
filósofo encontraba resonancia y donde su obra fue recibida y custodiada haciendo posible su publicación póstuma. Desde ese momento y hasta nuestros días, la obra de Spinoza ha encontrado muy diversas formas de multiplicación así como no le han faltado detractores. Por lo tanto, es un universo vasto y múltiple el de los relevos del pensamiento spinoziano, y el siglo XX ha sido particularmente rico en las lecturas de Spinoza, con aportes tan relevantes como el de Gilles Deleuze, Alexandre Matheron, Etienne Balivar, Antonio Negri, entre otros; y en nuestras latitudes latinoamericanas los estudios de Marilena Chauí y Diego Tatián, también entre otros, configuran un nuevo y creciente círculo de spinozismo .

Pero también, y este es el sentido que quisiera desplegar en este texto, afirmar la contemporaneidad de su pensamiento puede referir a su radical actualidad. Esto es, la posibilidad de poner a funcionar relaciones del pensamiento filosófico de Spinoza en nuestras preguntas y problemáticas actuales, como potencia que habilita la emergencia de lo novedoso.

Entonces, primero quisiera abrir una breve digresión sobre la cuestión de cómo alcanzar la posición de actualidad en el pensamiento. ¿Qué es lo que hace actual a un modo filosófico del pensar? ¿Cómo se determina la actualidad en el pensamiento? Para ensayar una respuesta a esta cuestión hago un breve pasaje por un texto de Foucault que nos brinda elementos a este respecto.

En 1984, a 200 años de la publicación del texto de Kant “¿Qué es la Ilustración?", Foucault publica un texto homónimo que convoca a pensar en la pregunta por el quién que somos. Señala que a partir de la filosofía kantiana se han abierto dos rumbos en el pensamiento filosófico. Por una parte se despliega toda una tradición de pensamiento que podría denominarse "una analítica de la verdad", que se ocupa fundamentalmente de establecer las condiciones bajo las cuales el conocimiento es verdadero. Pero también se abre todo otro conjunto de interrogantes ligadas a pensar

¿en qué consiste nuestra actualidad?, ¿cuál es el campo hoy de experiencias posibles? No se trata ya de una analítica de la verdad sino de lo que podría llamarse una 
ontología del presente, una ontología de nosotros mismos. (...) una ontología de la actualidad; (...) (Foucault, 2009, p. 39).

Foucault se refiere al texto original de letra kantiana como un texto inaugural en la tradición filosófica, en él por primera vez un filósofo es llamado a pensar la actualidad de su pensamiento, no como pertenencia a una determinada tradición, sino como pertenencia a un nosotros del cual es parte y en el cual encuentra su sentido el pensamiento.

La cuestión que a mi juicio surge por primera vez en este texto de Kant es la cuestión del presente, la cuestión de la actualidad: ¿qué es lo que ocurre hoy?, ¿qué es lo que pasa ahora?, ¿qué es ese "ahora" en el interior del cual estamos unos y otros y que define el momento en el que escribo? (Foucault, 2009, p. 29).

Es en este campo de actualidad, como ejercicio de pensamiento sobre el quién que somos, que el pensamiento de Spinoza se presenta como una potencia que porta elementos para la emergencia de novedad, para instaurar otros modos de concebirnos y de hacer del mundo.

La ontología del presente, hay que concebirla como una actitud, como un ethos, como una vida filosófica en la que la crítica de lo que somos es, simultáneamente, un análisis histórico de los límites que nos son impuestos y un experimento de la posibilidad de rebasar esos mismos límites (Foucault, 1994, p. 42).

Este ethos implica un ejercicio de nosotros mismos orientado a producir modos posibles de conducir nuestras vidas. ¿Cuál es hoy nuestro campo de experiencias posibles? Esta es una pregunta que sólo podemos responder haciendo experiencia de ella, reconociendo los límites histórico-sociales que hacen parte de nuestra constitución y construyendo condiciones para generar otro campo de posibles, otros modos de lo humano no sobredeterminados por las formas instituidas.

Nos es necesario generar aperturas a nuevos posibles que nos permitan salir de la reproducción de los modos cristalizados de hacer experiencia de lo humano y para 
ello es necesario interrogar el suelo de nuestro pensamiento, realizar una ontología de nosotros mismos.

El saber de la contingencia de las actuales formas de nuestra subjetividad es lo que nos permite un primer gesto en la transformación de las relaciones que nos constituyen. Una ontología del presente como actitud crítica de nosotros mismos que permite abordar el presente para transformarlo, afirma la posibilidad de inaugurar experiencias de lo humano novedosas.

Spinoza deviene entonces un pensador contemporáneo en la medida en que las relaciones que afirma se actualizan en la trama de un pensamiento sobre nuestro presente. Su actualidad no es un elemento a descubrir o develar en las formas vigentes de nuestros modos de pensarnos, sino más bien un gesto afirmativo que en su realización efectúa la actualización.

Lo actual en el pensamiento es mucho menos una identidad con lo contemporáneo y mucho más una complicidad con las potencias innovativas del pensamiento que busca expresarse bajo otras figuras. La actualidad es el gesto mismo, es el ser en acto del ejercicio de pensar, su efectuación en tanto que trama de relaciones que constituye su propio presente.

En ese ejercicio entonces, este trabajo intenta aceptar la interrogante por nuestras condiciones actuales para la generación de tramas comunes, y la pregunta por la producción de formas de vida colectiva, realizando una lectura de Spinoza.

La riqueza y complejidad del pensamiento de Spinoza supone una dificultad a la hora de querer extraer de él líneas específicas. El plegamiento de las dimensiones ética, política y ontológica, nos fuerza a realizar un ejercicio de pensamiento que atraviese los compartimentos habituales que separan estas dimensiones. Desplegar la pregunta por lo común entonces, requiere trazar el plano de pensamiento spinoziano. 


\section{Ontología política: ser en común}

En la filosofía de Spinoza hay una implicación entre ontología, ética y política, que es constitutiva de su pensamiento. Tal implicación se expresa a lo largo de la argumentación de la Ética (1980) y en sus conexiones con los Tratados (Tratado Político, 1986a y Tratado Teológico Político, 1986b) donde esa implicación toma cuerpo. Ontología, física, teoría del conocimiento, ética y política se articulan y componen juntas una filosofía de la potencia y la liberación. Conexión intrínseca que es más que correspondencia de la ética y la política a una metafísica previa, se trata de una complicación en el proceso mismo de la vida humana.

Para pensar una política del ser y para considerar el régimen político más adecuado para el gobierno, Spinoza sostiene que es necesario tener presente los resultados de su investigación ontológica. Su reflexión política parte de las conclusiones a las que llegó en las investigaciones de la Ética demostrada según el orden geométrico (Spinoza, 1980).

Es un lugar común el de la consideración en Spinoza de la realidad en su conjunto como sustancia única, llamada Dios o la Naturaleza. Martial Gueroult (1974) considera que ya en el Tratado breve Spinoza se propone la unidad de Dios y la Naturaleza por medio de los conceptos de causa sui y de causa inmanente y su identidad por la identificación de los atributos de Dios y los atributos constitutivos de la Naturaleza.

Desde la demostración de la proposición VIII del libro I de la Ética (1980) en la que Spinoza afirma que "no existe más que una única substancia con el mismo atributo (por la Proposición 5) y que el existir pertenece a su naturaleza (por la Proposición 7)", (p.33), pasando por la proposición XIV en la que advierte que "no puede darse ni concebirse substancia alguna excepto Dios" (p. 40), a la proposición XVIII en la que dice que "Dios es causa inmanente pero no transitiva de todas las cosas" (p. 47), Spinoza va trazando el recorrido que excluye la posibilidad de una pluralidad o dualidad de sustancias para afirmar una única sustancia. 
La sustancia es causa sui, su esencia implica su existencia. En la proposición VII del libro I de la Ética (1980) leemos: "A la naturaleza de una sustancia pertenece el existir" (p. 33) y en la XVII: "Dios obra en virtud de las solas leyes de su naturaleza, y no forzado por nadie" (p. 39). La naturaleza o sustancia obra por su sola necesidad, no obra de acuerdo a fin algún exterior a ella.

En la proposición XXXIV de la primera parte de la Ética (1980), "La potencia de Dios es su esencia misma" (p. 61). Y más adelante en el escolio de la proposición III de la segunda parte, "La potencia de Dios no es otra cosa que la esencia activa de Dios, y, por tanto, nos es tan imposible concebir que Dios no actúa como que Dios no existe" (p. 72). El ser de la sustancia es productivo, y en su infinita productividad está el ser causa de sí misma.

«Ante nosotros, ahí, la naturaleza: despliegue de potencia autónoma infinita. Nada en ella sabe de sentidos o finalidades; sólo libertad absoluta de la absoluta libertad inmanente" (Albiac, 1987, p.310).

Con Spinoza, la idea de trascendencia es sustituida por la de inmanencia, de tal manera que Dios se concibe simultáneamente a la aprehensión del mundo. Dios es la causa inmanente de todas las cosas, y por eso todo lo que es, es en Dios.

Tomada en su sentido único y en su única modalidad, la causa es esencialmente inmanente, es decir, permanece en sí para producir (en oposición a la causa "transitiva") y el efecto tampoco sale de ella (por oposición a la causa emanativa) (Gebhardt, 1977, p. 50.)

La sustancia y los atributos son la sustancia en tanto que causa de sí, configuran lo que Spinoza denomina como la Natura Naturans, es decir, naturaleza naturante. En cambio los modos de la sustancia, cuya esencia no implica la existencia, son la Natura Naturata, naturaleza naturada. Los individuos, en tanto que naturaleza naturada, son y existen en la sustancia. No está en la potencia de su esencia el existir, por tanto no pueden concebirse por sí mismos sino siendo en la sustancia.

La distinción de Natura Naturans y Natura Naturata diferencia el aspecto productor del aspecto de lo producido. Sin embargo, por el concepto de inmanencia, lo 
productor y lo producido actúan a un mismo nivel, es decir, la producción la efectúa una causa inmanente y no transitiva, el efecto se produce sobre la misma causa y no en ningún lugar fuera de la misma.

(...) la naturaleza «naturante» es la naturaleza en tanto que naturante, la naturaleza considerada en su aspecto productor, aspecto aislado por abstracción; y la naturaleza «naturata» o los modos, son las estructuras que se dan al desplegarse, la naturaleza en tanto que naturata; pero en realidad no hay más que individuos más o menos compuestos, cada uno de los cuales (naturante y naturato a la vez) se esfuerza por producir todo lo que puede, y por producirse y reproducirse a sí mismo produciendo todo lo que puede (...) (Matheron, 1982, p. 20).

Los modos modifican a la sustancia permaneciendo en ella. La causa permanece en el efecto y el efecto en la causa. Al decir de Annabel Teles (2010) se trata de un ser que "produce y al producir se produce" (p. 68). Esta es la operación de la causa eficiente inmanente. La naturaleza es potencia, potencia de obrar, potencia genésica, potencia que actúa por su propia necesidad.

Todos los individuos, todos los modos, gozan de una misma dignidad a nivel ontológico. Esta igualación jerárquica de los modos impide toda apelación metafísica a instancias de superioridad que regulen los modos del ser, lo que constituye un plano político que se instaura a nivel ontológico. Para realizar este movimiento dos operaciones filosóficas fueron fundamentales: la afirmación de una única sustancia que es causa de sí misma y contiene en sí todas las modalidades del ser, y la formulación de la causa productiva o del movimiento genésico como causa eficiente inmanente.

Al modo geométrico, Spinoza traza un plano de inmanencia, donde se dibuja la expresión del modo humano como parte de la naturaleza. Una única sustancia o naturaleza, con infinitos atributos que se expresan de infinitas maneras, configura el ser. El ser se expresa de infinitas maneras. Los individuos o modos, son estas modalidades de la sustancia, o expresiones de la misma, que es una y la misma para todos los modos que la expresan. 
Desde la inmanencia se postula una concepción que entiende al ser como la noción más universal de todas y, en consecuencia, común a todo lo que es. El ser se diría de la misma manera para todos los entes. Esta ontología inmanente constituye una política del ser con enormes efectos al nivel de una ética de las existencias y de una política de los cuerpos. Efectos que no deben considerarse como determinaciones de una teoría ontológica sobre los modos individuales, sino más bien, como se dijo previamente, una co-implicación de dimensiones que se expresan mutuamente.

En palabras de Diego Tatián (2019) "la idea de una naturaleza común y en común; la naturaleza como noción común es el gran presupuesto spinozista de igualdad que aloja una potencia de diversidad no jerárquica, una fuerza productiva de infinitas experiencias sociales" (p. 91).

De este trazado de algunas líneas del plano ontológico en Spinoza, se extrae una formulación de lo común, lo común en el ser, el ser en común. Una cita de Jean Luc Nancy encuentra resonancia para ilustrar este sentido ontológico de lo común:

Hay algo más común que ser, que el ser? Somos. Lo que compartimos es el ser, o la existencia. No estamos aquí para compartir la no-existencia, ella no es para ser compartida. Pero el ser no es una cosa que poseyeramos en común. El ser no es en nada diferente de la existencia cada vez singular. Se dirá, por tanto, que el ser no es común en el sentido de una propiedad común, sino que es en común. El ser es en común. Hay algo que sea más simple constatar? (Nancy, 2001, p. 151).

\section{El pliegue ético: Individuo en trama común}

Una de las principales dificultades para poder pensar lo común es la perspectiva del sujeto como figura de lo humano. La imagen tradicional del sujeto moderno se encuentra en la base de la escisión entre individuo y colectivo.

La imagen esquemática del sujeto moderno, cuya fundación suele ubicarse en la filosofía de Descartes, afirma al sujeto como instancia con una conciencia interior 
que posee voluntad y autodeterminación (Descartes, 1977). Se afirma una interioridad del individuo y una exterioridad de las relaciones. Toda relación es exterior y el sujeto es término de dicha relación, nunca relación en sí mismo. La situación epistemológica de sujeto y objeto expresa los elementos fundamentales de esta conceptualización: términos exteriores entre ellos y exteriores a la relación que los vincula; y el proceso de entrar en relación es un proceso de objetivación que supone siempre la delimitación a priori de aquello que se constituye en objeto.

Este modo de comprensión del sujeto configura un cierto campo político que también se expresa en el problema de la representación política. En el modelo político de la soberanía, el Estado representa una voluntad común de velar por los intereses del colectivo para lo cual el individuo sacrifica ciertas libertades e intereses en aras de los beneficios que obtiene de su pertenencia a la sociedad (Hobbes,1982). Estas formas de comprender lo colectivo se contraponen a la dimensión de lo individual. Las condiciones de generación de lo colectivo implican una pérdida para el individuo y se abre un campo de tensiones frente al cual las distintas posiciones políticas inclinan la balanza en un sentido $u$ otro: mayor defensa de las libertades individuales o disminución de las libertades en defensa de un bien colectivo.

Encontramos en el pensamiento de Spinoza otra configuración del campo político donde esta tensión individuo/colectivo se disuelve. Para ello es necesario acceder a una noción de individuo que implica en sí mismo la dimensión de lo colectivo.

Spinoza define la cosa singular, el individuo, como una cooperación de actividad orientada por un esfuerzo común. Así la proposición VII del libro II de la Ética (1980) dice:

Entiendo por cosas singulares las cosas que son finitas y tienen una existencia limitada; y si varios individuos cooperan a una sola acción, de tal manera que todos sean a la vez causa de un solo efecto, los considero a todos ellos en este respecto, como una sola cosa singular (p. 70). 
En esta proposición se expresa con claridad que aquello que constituye al individuo (la cosa singular) son las relaciones que efectúa, entendidas como acción. La unidad proviene de la comunidad de operación, siendo el individuo una composición de individuos unidos como constituyentes de una causalidad única. Marilena Chauí enfatiza esta comprensión de los individuos que "constituyen un solo cuerpo cuando, aplicándose unos a otros o cuando, comunicando sus movimientos unos a otros, forman una unión de cuerpos que es el individuo" (2004, p. 142). La singularidad surge como composición de individuos que concurren a una misma acción: singularidad en acto.

El concepto de individuo es el de un ser en relación. Todo individuo es una cierta potencia, una capacidad de afectar y ser afectado. Esto implica una comprensión de individuo como un conjunto de relaciones en efectuación (Deleuze, 2008). Es el ejercicio de la potencia lo que define al individuo y no una determinación formal del sujeto. Al pensar al individuo como ese conjunto de relaciones, conjunto de prácticas, necesariamente se introduce una dimensión colectiva en el plano individual. Las relaciones se efectúan constantemente configurando planos colectivos.

La esencia de un ser singular es su actividad, o sea, las operaciones y acciones que realiza para mantenerse en la existencia, y esas operaciones y acciones son lógicamente anteriores a su distinción como irracionales o racionales, verdaderas o falsas, buenas o malas. (Chauí, 2004, p. 224)

Esta conceptualización del individuo enfatiza dos aspectos fundamentales. Por un lado se inscribe al individuo en una dimensión colectiva: todo individuo, al ser una potencia relacional, es en sí mismo colectivo. Por otra parte, es el ejercicio práctico lo que define al individuo: en qué consiste esa potencia singular no es algo que está determinado a priori, ni puede fijarse en una identidad. Qué potencias efectúa un individuo es algo que sólo podemos conocer en la misma efectuación. De manera que el concepto de individuo responde más que a una persona o a un grupo, a un cierto ejercicio. Es en ese sentido que se habla de individuación como proceso en constante transformación y variación. Los individuos son cortes en un proceso constante de 
individuación, de relaciones que se componen y se descomponen generando nuevas configuraciones que efectúan potencias nuevas.

En la perspectiva particular del modo humano, esta cooperación de acciones se realiza en la figura del conatus, el esfuerzo por perseverar en el ser.

En la Proposición VII del libro III de la Ética (1980) Spinoza identifica el conatus con la esencia de las cosas singulares: "El esfuerzo con que cada cosa intenta perseverar en su ser no es nada distinto de la esencia actual de la cosa misma" ( $p$. 131). En la primera de las Definiciones de los Afectos del libro III de la misma obra leemos "El deseo es la esencia misma del hombre en cuanto es concebida como determinada a hacer algo en virtud de una afección cualquiera que se da en ella." (p. 170). Y en el libro IV, en la demostración de la Proposición XVIII, dice: "El deseo es la esencia misma del hombre, esto es, el esfuerzo que el hombre realiza por perseverar en su ser" (p. 199).

Este esfuerzo, en el modo humano, se llama potencia-deseo. La esencia misma del hombre es el deseo, de modo que hay una identificación entre la esencia y el conatus como potencia de perseverar en el ser. De manera que arribamos a una comprensión ética de los modos de existencia como potencias-deseo en relación que en su esfuerzo por perseverar en su existencia se afectan unas a otras, complicándose en tramas afectivas que aumentan y disminuyen la capacidad de obrar de los individuos.

En la Ética (1980), Spinoza logra una comprensión del modo humano como parte de una naturaleza que obra según su propia necesidad, que hará imposible concebir, en adelante, a lo humano como una figura aislada o entender a su comportamiento como una excepcionalidad en el mundo. Afirmación del individuo como instancia de individuación siempre colectiva. No hay individuo que no sea conformado por un conjunto de relaciones que funcionan con partes exteriores que perforan su individualidad. La potencia singular de cada individuo, su capacidad de afectar y ser afectado, es siempre en relación. No habría interioridad del individuo y exterioridad del colectivo. "Lo común y lo singular no se oponen. La potencia colectiva 
se singulariza y contribuye a la singularización de los elementos que constituyen su propia trama afectiva" (Teles, setiembre de 2018, p. 10).

Encontramos en la obra de Gilbert Simondon una teoría de la individuación colectiva, filósofo que no se proclama parte del spinozismo, pero que sin embargo aporta elementos que podrían hacer un campo común con la obra de Spinoza a este respecto. Simondon afirma que la individuación colectiva es la que asocia el individuo a un grupo. Esta asociación no estará dada por lo que se encuentra en ellos de individuado sino por "la realidad preindividual que lleva en sí y que, reunida a la de los demás individuos, se individua en unidad colectiva" (Simondon, 2015, p. 16). Lo colectivo entonces no será la sumatoria de individuos sino una actualización del ser en tanto que colectivo. Los individuos Ilevan consigo potenciales que pueden devenir colectivo, pero no están individuados. El individuo participa del descubrimiento de la significación de lo colectivo a través de su naturaleza, pero no de su naturaleza individuada sino de la naturaleza asociada a ésta, lo preindividual que lleva. "Lo colectivo es una individuación de las naturalezas asociadas a los seres individuados" (Simondon, 2015, p. 389).

El concepto de naturaleza está refiriendo a los potenciales preindividuales que pueden asociarse al concepto de physis de los filósofos presocráticos como "realidad de lo posible, bajo las especies de este apeiron del que Anaximandro hace surgir toda forma individuada" (Simondon, 2015, p. 389). A través de esa carga de naturaleza que el individuo porta, es que el ser no es sólo individuado, es ser individuado y naturaleza. Esa carga de naturaleza es el potencial de futuras individuaciones así como la condición de comunicación con los demás seres individuados y la naturaleza asociada a ellos.

El sujeto es entonces el "conjunto formado por el individuo y la carga de apeiron que lleva consigo" (Simondon, 2015, p. 390).

Esta referencia nos permite enfatizar la concepción de individuo como actividad, potencia en acto, que subraya Marilena Chauí. Así como también su pertenencia a una potencia siempre mayor, la Naturaleza, por la que no se agota la 
Spinoza, potencias de lo común

potencia individuada en su forma actual sino que siempre está en relación a una potencia mayor capaz de mutar el campo de relaciones actuales y generar otros devenires.

\section{La razón de lo común}

La definición ontológica de los individuos como modos expresivos de la naturaleza produce la determinación de la existencia como radicalmente en relación. En la medida en que el modo no es causa de sí, es afectado por causas externas que lo determinan, que favorecen o impiden el despliegue de su potencia. Por lo tanto, la existencia no tiene ninguna posibilidad de autodeterminación voluntaria, sino que siempre tendrá que vérselas con un campo de relaciones que juega a favor y en contra, según las circunstancias, de su potencia de vida.

Atender al campo de relaciones de afección desde el punto de vista del individuo es el arte de los modos de existencia. Cada quien en su ejercicio singular realiza esfuerzos por perseverar en su ser, es el conatus en tanto que esencia del modo humano. Esos esfuerzos, siempre limitados por las fuerzas exteriores, pueden ser conducidos por la razón y orientados a un despliegue activo de la potencia.

La razón, en su génesis, es el esfuerzo de organizar los encuentros en función de las conveniencias y de las disconveniencias percibidas. La razón en su actividad misma es el esfuerzo de concebir las nociones comunes, por lo tanto de comprender intelectualmente las conveniencias y las disconveniencias mismas. Cuando formamos una noción común, nuestra alma se supone que «se sirve de la razón»: llegamos a la posesión de nuestra potencia de actuar o de comprender (Deleuze, 1996, p. 273).

La organización de los encuentros con otros cuerpos de modo que convengan con las relaciones que los constituyen, es lo que configura el plano ético de los modos de existencia. Los humanos, como parte de la potencia infinita de la naturaleza, son causa sólo parcial de los acontecimientos que pueblan sus vidas. Spinoza realiza una distinción entre pasiones y afectos activos que se elabora sobre esta vulnerabilidad de lo humano a los efectos de las causas exteriores. 
En el libro III de la Ética (1980), en la primera de las Definiciones, escribe: "Llamo causa adecuada aquella cuyo efecto puede ser percibido clara y distintamente en virtud de ella misma. Por el contrario, llamo inadecuada o parcial aquella cuyo efecto no puede entenderse por ella sola"(p.124). Y en la segunda definición se lee:

Digo que obramos, cuando ocurre algo, en nosotros o fuera de nosotros, de lo cual somos causa adecuada; es decir, cuando de nuestra naturaleza se sigue algo, en nosotros o fuera de nosotros, que puede entenderse clara y distintamente en virtud de ella sola. Y, por el contrario, digo que padecemos, cuando en nosotros ocurre algo, o de nuestra naturaleza se sigue algo, de lo que no somos sino causa parcial (p. 124).

Obramos cuando somos causa adecuada de lo que sucede en nosotros, padecemos cuando somos causa parcial. Esta distinción irá acompañada de una diferenciación de tres géneros de conocimiento que marcan distintos umbrales de la potencia de comprensión-acción. El primer género de conocimiento está constituido por ideas inadecuadas provenientes de la imaginación, por las afecciones pasivas y su concatenación. La percepción se desprende del efecto que tienen las causas sobre el cuerpo afectado, pero queda separado de las mismas. Este conocimiento es por experiencia vaga, y no puede sino hablar más de la constitución del cuerpo afectado que de la relación de afección que está produciéndose.

En el segundo género de conocimiento "me dice todo sobre las relaciones que componen y descomponen los individuos, el segundo género procede por nociones comunes."(Deleuze, 2008, p. 450). Las nociones comunes son las ideas de relación. Son las nociones de las las composiciones de relaciones.

Cuando en la naturaleza se quieren considerar nociones de composiciones de relaciones, no pueden hacerse la idea adecuada de una relación compuesta sin formar al mismo tiempo una idea de Dios como fundamento de las relaciones que se componen. Por tanto, ustedes van necesariamente de la noción común a la idea de Dios como fundamento de todas las relaciones. En efecto, la idea de Dios estaría definida, a ese nivel, como el fundamento de todas las composiciones de relaciones (Deleuze, 2008, p. 450). 
Las nociones comunes, entonces, son comunes en la medida en que lo que expresan es la comunidad de varios cuerpos, de varios individuos, tomados bajo una misma relación. Deleuze dirá luego que esas ideas son adecuadas en la medida en que expresan la esencia de Dios o la Naturaleza.

Pero una vez que estoy en la idea de Dios me doy cuenta de que hay allí algo más que en las nociones comunes. De modo que ella tiene una cara vuelta hacia otra cosa. ¿Qué es? Dios como continente, como siendo él mismo una esencia que contiene todas las esencias. Todas las esencias singulares están comprendidas, contenidas en la idea de Dios. (Deleuze, 2008, p. 451).

A este nivel de conocimiento de las esencias singulares, corresponde el tercer género de conocimiento. Por lo tanto, del primer al segundo género habrá un movimiento activo de la potencia que logra formar ideas adecuadas a través de la composición de cuerpos comunes; y la formación de estas ideas, en la medida en que expresan la esencia de Dios que las contiene, es ocasión para el acceso a la comprensión intuitiva de las esencias singulares, llamado también conocimiento del tercer género o ciencia intuitiva.

Lo común está allí y opera en las posibilidades conectivas o compositivas de las potencias, es lo que hace que las partes sean partes de un todo. $Y$ esto es independiente de los modos en los que la imaginación se figure que ello sucede. Pero cuando hay un conocimiento racional de la experiencia de comunidad, que es experimentado con alegría, se está afirmando un plano de consistencia de lo común.

En la acción, el conatus está internamente fortalecido, sus partes se armonizan y se equilibran recíprocamente; simultáneamente, los hombres se perciben unos a otros como valiosos, reconocen lo que poseen en común, descubren que la utilidad recíproca y la comunidad de afectos los fortalecen y por eso pasan de la discordia a la concordia (Chauí, 2004, p. 226).

La distinción entre géneros de conocimiento no puede inscribirse en una teoría epistemológica sin más. Todo el sistema de imbricación de distintas capas que se despliegan en la Ética (1980), es expresión de una teoría del conocimiento que no 
puede separarse de un devenir ético en un cierto campo político, y cuya condición y también su efecto se produce en un plano ontológico. El primer género expresa la vulnerabilidad y fragilidad de las potencias de los individuos expuestas a las fuerzas exteriores que pueden aumentar o disminuir su potencia de actuar en estados mínimos de autonomía y máximos de individualidad; el movimiento del segundo género de conocimiento implica la capacidad de la razón como fuerza afectiva que puede orientar la potencia en un devenir ético activo a través de la formación de ideas adecuadas, en la comprensión de las causas de las afecciones y afectos que la constituyen y la consecuente conformación de cuerpos comunes que aumentan la potencia colectiva de obrar; el conocimiento de la ciencia intuitiva de las esencias singulares implica las ideas de relación y las complica en el conocimiento de las esencias en las que son tomadas las relaciones, y en la experiencia de la naturaleza como eternidad, fondo de inmanencia y a la vez presencia absoluta y actual.

\section{La política: la institución de la potencia común}

Se habla de la presencia de un marcado realismo político en la obra de Spinoza (Tatián, 2019). Esto hay que entenderlo no en el sentido de un privilegio de la realidad ya instituida para que de allí se desprenda el análisis y la configuración del campo político, sino en el sentido de una política despojada de elementos morales que juzga los acontecimientos políticos en base a aspiraciones idealistas. Así, el célebre inicio del Tratado Político (cuyo tono también está presente en el prefacio al libro III de la Ética (1980)):

Los filósofos conciben los afectos, cuyos conflictos soportamos, como vicios en los que caen los hombres por su culpa. Por eso suelen reírse o quejarse de ellos, criticarlos o (quienes quieren aparecer más santos) detestarlos. $Y$ así, creen hacer una obra divina y alcanzar la cumbre de la sabiduría, cuando han aprendido a alabar, de diversas formas, una naturaleza humana que no existe en parte alguna y a vituperar con sus dichos la que realmente existe. En efecto, conciben a los hombres no como son, sino como ellos quisieran que fueran. De ahí que, las más de las veces, hayan escrito una sátira, en vez de una ética y que no hayan ideado jamás una política que 
pueda llevarse a la práctica, sino otra, que o debería ser considerada como una quimera o sólo podría ser instaurada en el país de Utopía o en el siglo dorado de los poetas, es decir, allí donde no hacía falta alguna" (Spinoza, 1986a, p. 77-78).

El realismo spinoziano se define desde el inicio en la configuración del campo político, al asumir como método una perspectiva de la política que piensa a hombres y mujeres en los términos de su propia naturaleza. No los hombres y mujeres que deberían ser según una imagen que sólo podemos gestar negando los afectos que nos componen, sino la afirmación de una política que hace de la afectividad su materialidad.

Esta posición que afirma la afectividad inmanente de lo humano como punto de partida de toda política, encuentra su primer fundamento en el plano ontológico formulado en la Ética (1980). En relación con el pensamiento spinoziano se plantea una modalidad política que, sin dejar de lado las modalidades estructurales, enfatiza las afecciones, los afectos y los efectos que constituyen el cuerpo político. Se trata de una "política afectiva que atiende a las tramas afectivas que constituyen a los seres en su despliegue" (Teles, 2010, p41), deja de ser el dominio exclusivo de la institucionalidad; atiende a la relacionalidad, al poder de afectar y ser afectado; expresa el interés por los procesos singulares y colectivos de constitución existencial. En otras palabras, presta atención al movimiento afectante y afectado, a la variación de la potencia de las singularidades y de lo común.

Un concepto fundamental para la constitución del plano político en Spinoza es el de Derecho Natural. El derecho de la Naturaleza en su conjunto y, por consecuencia, el derecho natural de cada individuo se extiende hasta donde llegan los límites de su poder; todo cuanto puede realizar un hombre en virtud de las leyes de su naturaleza, lo lleva a cabo con un derecho natural y pleno (Spinoza, 1986a). Spinoza explica que el comportamiento de los hombres no está determinado por ninguna regla excepcional en la naturaleza, y que, en cambio, los hombres se rigen por las mismas reglas de toda la naturaleza. "Es imposible que el hombre deje de ser una parte de la naturaleza y que no siga el orden común de ella" (1980, p. 242), pero las reglas de la naturaleza van más 
allá de los intereses humanos y no estén orientadas a buscar lo que es más útil a lo humano.

Este poder del Derecho Natural es el poder del conatus, que fue definido en la Ética (1980) como el esfuerzo por perseverar en el ser, que determina todos los actos del hombre y por los cuales subsisten los hombres, pues tal como se infiere del conatus todo cuanto es tiende a conservar su ser en la medida de su poder (Spinoza, 1986a). Todo lo que es, se esfuerza por existir, y en este esfuerzo no hay diferencia entre quienes obran conforme a la razón y quien no lo hace.

El conatus se presenta como principio de individuación y diferencia, y como causa de las acciones humanas tanto en estado natural como en la constitución de un estado político con la conformación del Estado. El conatus como potencia de insistencia en la existencia da cuenta de que la asociación de los hombres no se funda en el miedo a la muerte, sino en la búsqueda de aumentar su potencia de existir.

En estado de naturaleza los humanos viven de acuerdo con las leyes de la naturaleza, por lo que no hay pecado y nada se prohíbe en el estado de naturaleza (Spinoza, 1986a). Se impide solo lo que no se puede, y lo que no se desea. El poder de cada uno legitima sus acciones en estado natural, pues todo lo que hace alguien por su poder lo hace con su máximo derecho.

En palabras de Marilena Chauí:

(...)la experiencia muestra y la geometría demuestra que el derecho natural no es razón, sino deseo y potencia, y que cada uno tiene tanto derecho como potencia tenga para ejercerlo (...) el hombre es originariamente potencia, siempre que se demuestre que él es una parte de la Naturaleza, pues la Naturaleza es una potencia de actuar, potentia agendi (2004, p. 239).

Este derecho absoluto a conservarse es lo mismo que decir el conatus y eso en el modo humano no era otra cosa que el deseo, en tanto que su esencia (Spinoza, 1980). Por tanto, decir que el derecho en el hombre se extiende hasta donde alcanza su poder, no es sino otro modo de decir que son las afecciones, en tanto que acciones y pasiones, las que mueven a los individuos. 
El uso de la razón determina el obrar en función de aumentar su perseverancia en el ser, por lo que los hombres serán libres en cuanto sigan su razón, y no en cuanto sean determinados por sus pasiones, es decir, en cuanto padezcan. "Cuanto más libre consideramos, pues, al hombre, menos podemos afirmar que puede no usar de la razón y elegir lo malo en vez de lo bueno" (1986a, p. 88-89). En el estado natural los individuos que se guían por la razón conocen los peligros a los que están expuestos en la medida en que están sometidos a las acciones de las fuerzas exteriores y al dominio de las pasiones. En estado de naturaleza el individuo no tiene ninguna oportunidad de realizar su libertad aún cuando se guíe por la razón.

(...) el estado político, por su propia naturaleza, se instaura para quitar el miedo general y para alejar las comunes miserias; y por eso busca, ante todo, aquello que intentaría conseguir, aunque en vano, en el estado natural, todo aquel que se guía por la razón (Spinoza, 1986a, p. 103)

El derecho natural no se fundamenta en la razón, sino en la fuerza o potencia para actuar. No es la razón lo que determina para cada uno el derecho natural.

(...) abandonar el estado de naturaleza es que el derecho a todas las cosas, que cada uno tenía por naturaleza, lo poseyeran todos colectivamente y que en adelante ya no estuviera determinado según la fuerza y el apetito de cada individuo, sino según el poder y la voluntad de todos a la vez (Spinoza, 1986a, 108).

De esta manera, el poder o derecho de naturaleza pasan a poseerlo en común todos los individuos. “(...) el derecho civil prolonga el derecho natural y la vida política es la vida natural en otra dimensión"(Chauí, 2004, p. 255).

No se trata de una cesión de la potencia a un soberano como es la imagen habitual del modelo contractualista. Es la fuerza que le otorga el poder instituyente de la multitud lo que sostiene la soberanía de un Estado, en cuanto su fuerza disminuye ésta desaparece. Spinoza escribe a Jarig Jelles, en la carta 50 "La diferencia entre Hobbes y yo, consiste en que yo conservo siempre incólume el derecho natural" (Rodríguez López-Abadía, 2017, p. 145). 
Regidos por el derecho de naturaleza, las potencias individuales sólo están impedidas de lo que no desean o lo que escape a sus medios de acción, lo percibido como malo o bueno descansa en función de la naturaleza de cada individuo y en el desconocimiento del orden y enlace de la naturaleza en su conjunto.

No existe justo o injusto, crimen u honor antes de la Ciudad, es decir que no hay pecado antes de la ley, pues la ley crea lo social y lo político, porque (...) la Naturaleza crea individuos, pero no crea pueblos (Chauí, 2004, p. 254).

Será la razón, en tanto que un modo de darse del deseo, aquella que muestre que conviene la unión de los múltiples, siendo esta fuerza la que funda la soberanía común.

(...) los hombres han debido entenderse mutuamente y hacer ejercitar comunalmente este derecho sobre todas las cosas que cada uno recibió de la naturaleza: han debido renunciar a la violencia de sus pasiones (apetitos individuales) y someterse a la voluntad y al poder de todos los hombres reunidos (Spinoza, 1986b, p.408).

Este plano político abre la brecha para pensar la democracia como una praxis que atiende al siempre abierto problema de la composición de las relaciones de fuerzas, es decir, al problema de la democracia como experiencia: conservación y expansión de las complejas relaciones entre las potencias. El pacto democrático no se sostiene por necesidad de la razón sino por la utilidad común. Por ello, si la utilidad desaparece el pacto se disipa retornando la fuerza al derecho natural. El principio de conservación implica incluir dentro del derecho positivo la sujeción como una utilidad común, por eso el pacto no puede consistir en la sumisión incondicional al libre arbitrio de otro.

“En la democracia (...) la vida política transcurre en un espacio donde los conciudadanos decidieron actuar de común acuerdo, o actuar en común, pero no abdicaron de su derecho natural a pensar y juzgar individualmente." (Chauí, 2004, p. 258)

El ejercicio de ciudadanía, la institución de un derecho civil, es efecto del poder instituyente de la multitud y dicho poder no cesa. El derecho natural, deviene en 
derecho civil en la configuración de condiciones propicias para el ejercicio de las potencias singulares y su despliegue colectivo que se encuentran en estado de riesgo en el estado de naturaleza. El hombre es lo más útil para el hombre y encuentran bajo la forma del derecho positivo las mejores condiciones para la realización de la asociación de potencias. Pero el derecho natural nunca cesa de estar presente, nunca se cede totalmente. Por lo tanto, ese derecho inalienable de existencia, es siempre potencia capaz de rebelarse frente a las sujeciones y de reconstituirse y reagruparse en las fuerzas de la multitud. Nunca se encuentra totalmente cristalizado, en tanto que individuación colectiva, siempre es también potencia aún no individuada, poder de indeterminación, apeirón que guarda posibilidades aún no realizadas.

(...) debería tratarse de llevar la democracia a su propio lugar de enunciación y de exposición: al en-común de este pueblo cuyo nombre lleva sin tal vez haber aún encontrado la vía, ni la voz, de su articulación. "Filosofía" y "comunidad" tienen esto en común: un imperativo categórico, anterior a toda moral (pero políticamente inequívoco, porque lo político en este sentido precede toda moral, en lugar de sucederla y de acomodarla), de no soltar el sentido en común (Nancy, 2001, p. 74),

Es quizás la democracia spinoziana la ocasión de encontrar esa voz y sean nuestros tiempos la oportunidad de articularla.

(...) la política es autoinstitución de la libertad que no tanto conserva sino más bien concreta al derecho natural y le confiere realidad, por lo que la libertad puramente individual es una postulación abstracta, en cuanto tal ínfima sino inexistente, apenas un ente de razón. En Spinoza la libertad (también la que llamamos "individual”) es un efecto de lo común, requerido por ella como su condición de posibilidad (Tatián, 2019, p. 32).

En Spinoza encontramos la necesidad de articular la experiencia política con un conocimiento adecuado de las causas, una razón afectiva que oriente las acciones en las vidas de los individuos. La regencia del estado de cosas requiere de una imaginación política capaz de trascender los datos empíricos y crear condiciones para el despliegue de potencias novedosas. Los modelos políticos que detestan o burlan la naturaleza humana al diseñar normatividades puras que son irreconciliables con la 
experiencia no encontrarán posibilidades de efectuación puesto que no encuentran en la naturaleza común de lo humano su potencia expansiva. Para trascender los límites de lo que nos es históricamente dado no debemos imponer un deber más allá de la experiencia sino generar las condiciones de una imaginación política que se encuentre en el ejercicio común de hombres y mujeres en su experiencia.

\section{Volver a pensar lo común y la comunidad}

"La pregunta por lo común, la comunidad y el comunismo es uno de los grandes legados del spinozismo, un legado tan difícil como raro." (Tatián, 2019, p. 71)

La pregunta por la posibilidad de lo colectivo fuerza a pensar modos de lo político no institucionales que permitan la afirmación y despliegue de la potencia colectiva. Modos que se sustraigan de la lógica de la política como gobierno de los otros y de la naturaleza, y que permitan la constitución de un plano común. La figura de lo común se presenta como ejercicio de la potencia que en su despliegue y composición arma cuerpos colectivos, expresa un modo de comprensión político que sale de la lógica individualizante. Lo colectivo no se trata ya de una agregación de individuos, sino de una potencia de lo común. Es la actualización de un plano colectivo que implica a los quienes en su efectuación pero que no parte de su individualidad. "La potencia colectiva se singulariza y contribuye a la singularización de los elementos que constituyen su propia trama afectiva" (Teles, setiembre de 2018, p.9).

En el ámbito del spinozismo hay un énfasis en la dimensión afectiva del campo político que está planteada desde su formulación ontológica, del ser como potencia en relación. Esto conlleva a una definición poco habitual de lo político y a un ejercicio ético de las relaciones que no puede nunca abandonar el registro afectivo. Lo que se instituye es efecto de estas relaciones, pero primero y con anterioridad lógica, hay una trama relacional de los cuerpos y afectos. En ese sentido la comunidad entendida como aquello que se determina desde una exterioridad no es posible desde este plano de pensamiento. El spinozismo afirma la dimensión afectiva como plano político. La política es el régimen de afecciones que nos constituye. $Y$ el ejercicio ético es el de 
tratar de aprender en el juego de las relaciones cómo generar composiciones que hagan posible sostener los modos de vida que deseamos.

Lo común en este campo conceptual es entendido como un efecto de composición de relaciones que genera nuevos individuos, cuerpo de cuerpos. La comunidad es afirmada como el cuerpo colectivo que se conforma por estas relaciones de lo común, es efecto de producción. Lo común no es propiedad ni sustancia, sino un conjunto de relaciones que componen un cuerpo y que está en constante mutabilidad y variación. En tanto que efecto de composición, lo común indica un aumento y expansión de la potencia colectiva de obrar. Qué es lo común o cómo gestar una comunidad es algo que nunca está dado de antemano ni puede determinarse como forma exterior, sólo en la experiencia y en las tramas relacionales podemos aprender sobre las condiciones que hacen posible la generación de un campo común. "Este modo de concebir lo común enfatiza lo singular, pregunta por lo humano y por su individuación" (Teles, setiembre de 2018, p. 6).

Se trata de una comprensión de lo político como producción de comunidad. (...) lo político spinozista no ha de ser pensado como un imperio dentro de otro imperio, sino como ese ámbito natural conformado por un juego dinámico de pasiones y de razones, de conflictos y de concordancias, de servidumbre y de libertad; una composición de potencias cuyo despliegue se opera en virtud de pasiones comunes- o más bien de afectos comunes- y de nociones comunes que serán la sustancia misma de la comunidad (Tatián, 2015, p. 147).

La comunidad por tanto no es algo que sucede como resultado de un sacrificio, no se produce a pesar de sus miembros, sino que es el efecto de constitución de un deseo. Entrar en comunidad con algo o alguien es una composición intrínseca que afecta las singularidades que se implican entre sí.

Las potencias que definen a los seres se complicarían así en totalidades dinámicas, parciales, abiertas, inclusivas, en la medida en que no obstruyan mutuamente su expansión y su capacidad de afectar y de actuar, sino que, al contrario, la favorezcan (Tatián, 2015, p.19). 
El plano actual de constitución de lo común no responde a ninguna de las figuras instituidas ni a las imágenes habituales sobre lo colectivo. Nuestro repertorio de formas no puede dar cuenta de los procesos novedosos. Es necesario interrogar y no prefigurar este campo de emergencias, desplegar un pensamiento en escucha que sea capaz de acompañar la movilidad afectiva de las transformaciones que nos acontecen. ¿Qué modos afectivos se están gestando? ¿qué otras posibilidades de ser y hacer en la naturaleza? Por ello, la urgencia de transformaciones a nivel del pensamiento, de la percepción y del modo de hacer que permitan prestar atención a los campos de resonancias, a las territorialidades existenciales que favorecen tonalidades afectivas activas y alegres.

"Diríamos que lo común es un reservorio de singularidades en variación continua, una materia inorgánica, un cuerpo-sin-órganos, un ilimitado (apeiron) apto para las individuaciones más diversas" (Pelbart, 2009, p. 23).

Cuando se concibe lo común como potencia vital indeterminada, multiplicidad que aloja y trama la singularidad en diferencia, no es posible pensarlo como propiedad, bien expropiable, o cualidad representable. Es ejercicio actual y no cesa de actualizarse. Esto no significa que las condiciones que hacen posible su constitución no peligren y estén amenazadas constantemente. Los regímenes actuales de producción de subjetividad en nuestras democracias liberales inscriptas en procesos globales de mercantilización de la vida, atentan contra las figuras emergentes de lo común y si bien los procesos de expropiación y de representación totalitaria no pueden capturar para sí esas potencias, sí tienen el poder de impedir sus despliegues, de cortar las tramas. Un poder que nunca es ni será total. Los procesos de resistencia se reinventan, por la experimentación inmanente de este común, por las composiciones y recomposiciones que lo llevan a cabo, por las nuevas figuras afectivas que se dibujan en el plano geométrico, por los nuevos posibles que a partir de ahí se abren.

"Lo común absoluto no es algo en sentido estricto sino lo que permite la irrupción, una y otra vez, de nuevas comunidades por obra de nociones comunes, de pasiones comunes y de acciones comunes" (Tatián, 2019, p. 70). 
Lo común se presenta entonces como potencia de actualización de afectos activos, de cuerpos colectivos y también fuerza de protección ante la indefensión natural de los individuos.

“La razón política como una razón afectiva común en virtud de la cual la comunidad se constituye pero también se defiende contra lo que la vulnera o la amenaza" (Tatián, 2015, p. 148).

En las relaciones de comunidad guiadas por la orientación razonable, relaciones de comunión de cuerpos y espíritus regidos por códigos de amistad y apoyo mutuo para la conservación en la existencia y el aumento de las potencias singulares, se realiza un anhelo político spinoziano y encontrar las condiciones para ello realiza una imaginación política urgente para nuestro presente.

\section{Referencias bibliográficas}

1. Albiac, G. (1987). La sinagoga vacía: un estudio de las fuentes marranas del spinozismo. Madrid: Hiperión.

2. Chauí, M. (2004). Política en Spinoza (F. Gómez, Trad.). Buenos Aires: Gorla.

3. Deleuze, G. (1996). Spinoza y el problema de la expresión. España: Muchnik Editores, S.A.

4. Deleuze, G. (2008). En Medio de Spinoza. Buenos Aires: Editorial Cactus.

5. Descartes, R. (1977). Meditaciones metafísicas con objeciones y respuestas (V. Peña, Trad.). Madrid: Alfaguara. (Primera edición 1641)

6. Foucault, M. (1994). ¿Qué es la llustración? (J. Dávila, Trad.). Actual, 28, 19-46.

7. Foucault, M. (2009). El gobierno de sí y de los otros: Curso en el College de France: 1982-1983 (H. Pons, Trad.). Buenos Aires: Fondo de Cultura Económica.

8. Gebhardt, C. (1977). Spinoza. Buenos Aires: Losada. 
9. Hobbes, T. (1982). Leviatán. Colombia: Editorial Skla. (Primera edición 1651)

10. Gueroult, M. (1974). Spinoza, tome I: Dieu. Paris: Editions Aubier-Montaigne.

11. Matheron, A. (1982). Prefacio. En Antonio Negri. L'anomalie sauvage (p. 20). Paris: PUF.

12. Nancy, JL (2001). La comunidad desobrada (P. Perera, Trad.) Madrid: Arena Libros.

13. Pelbart, P. (2009) Filosofía de la deserción: nihilismo, locura y comunidad (S. García Navarro y A. Bracony, Trad.). Buenos Aires: Tinta Limón.

14. Rodríguez López-Abadía, A. (2017). Correspondencia de baruch de spinoza con algunos personajes notables. Digilec 4, 132-158.

15. Simondon, G. (2015). La individuación a la luz de las nociones de forma y de información (P. A. Ires, Trad.). Buenos Aires: Cactus.

16. Spinoza, B. (1980). Ética: demostrada según el orden geométrico. (V. Peña, Trad.). Madrid: Edit. Orbis. Hyspamérica. (Primera edición en 1677).

17. Spinoza, B. (1986a). Tratado político. (A. Domínguez, Trad.) Madrid: Alianza Editorial. (Primera edición 1677)

18. Spinoza, B. (1986b). Tratado Teológico Político. (A. Domínguez, Trad.) Madrid: Alianza Editorial. (Primera edición 1670)

19. Tatián, D. (2015). La cautela del salvaje. Pasiones y política en Spinoza. Buenos Aires, Argentina: Editorial Adriana Hidalgo.

20. Tatián, D. (2019). Spinoza disidente. Buenos Aires: Tinta Limón.

21. Teles, A. (2010). Política Afectiva. Buenos Aires, Argentina: Editorial La Hendija.

22. Teles, A. (setiembre de 2018). La inquietud por lo común, por la insistencia en las prácticas libertarias. Un aporte filosófico desde el Río de la Plata. En F. Morales Calatayud (Presidencia), Coloquio "La institución de lo común en el mundo contemporáneo". Actividad preparatoria del I Congreso Internacional de Psicología. Montevideo, Uruguay, 